\title{
Psychiatric referrals since the Abortion Act 1967
}

\author{
F. E. KENYON \\ M.A., M.D., M.R.C.P., D.P.M. \\ Consultant Psychiatrist, Warneford Hospital, Oxford; \\ Clinical Lecturer, University of Oxford
}

\section{Summary}

During the 1st year of the Abortion Act, 1967, sixty-five patients were seen for a psychiatric opinion. Of these $50 \%$ were single, $36 \%$ married and $14 \%$ separated or divorced.

Referral was by the general practitioner in $60 \%$, gynaecologist $36 \%$ and 'other' $4 \%$.

Mean length of psychiatric history was 18.9 months. Half had had unhappy childhoods and family relationships were frequently disturbed. Four $(6 \%)$ were University students.

Mean length of pregnancy was 11.0 weeks and for $87 \%$ of the single patients it was their first; for $36 \%$ of the married group it was their third. In fourteen $(21 \%)$ the pregnancy resulted from a contraceptive failure.

There was a previous psychiatric history in $69 \%$. The commonest diagnosis was depression, mainly of neurotic type $(52 \%)$ but $29 \%$ had no gross psychiatric disorder.

Termination of pregnancy was recommended in thirty-two $(49 \%)$, this included six where sterilization was also advised.

\section{Introduction}

The Abortion Act 1967 became law on 27 April 1968 and laid down certain conditions under which termination of pregnancy could be recommended so that prosecution under the Offences gainst the Person Act 1861 would not follow. The main provisions of the Abortion Act are contained in Section $1(1)$ and it is these which are quoted on the forms which have to be completed.

It is laid down that a person shall not be guilty of an offence under the law relating to abortion when a pregnancy is terminated by a registered medical practitioner if two registered medical practitioners are of the opinion, formed in good faith, that:

(1) The continuance of the pregnancy would involve risk to the life of the pregnant woman greater than if the pregnancy were terminated;

(2) The continuance of the pregnancy would involve risk of injury to the physical or mental health of the pregnant woman greater than if the pregnancy were terminated;

(3) The continuance of the pregnancy would involve risk of injury to the physical or mental health of the existing child(ren) of the family of the pregnant woman greater than if the pregnancy were terminated;

(4) There is a substantial risk that if the child were born it would suffer from such physical or mental abnormalities as to be seriously handicapped.

It is then stated in Section 1(2) that in determining whether the continuance of a pregnancy would involve such risks of injury to health, account may be taken of the woman's actual or reasonably foreseeable environment. This latter has been widely misinterpreted as the 'social clause' with the implication that termination could be carried out simply because of adverse environmental circumstances; from the actual wording of the Act this is patently not so, it merely stipulates that in the overall assessment of the risk to health environmental factors can also be taken into account. This is standard psychiatric practice in any case.

Many other criticisms of the Act have been made, particularly as to its actual wording in that many feel it is too imprecise and certain conditions are not mentioned at all. For instance there is nothing in the Act making abortion permissible for rape or because the girl was under the 'age of consent' (age 16).

The phrasing of the first clause about risk to the life of the pregnant woman is not very satisfactory as statistics could be produced to show that mortality from childbirth is greater than from therapeutic abortion. But from the psychiatrist's point of view this clause could be used for suicidal risk, this not being specifically mentioned in the Act.

The second clause allows a wide interpretation and is the one most commonly invoked. In assessing a particular patient the possible sequelae to abortion itself must also be considered.

The third clause, in one important respect, goes against the accepted tradition of the woman's health being the primary consideration and in theory allows abortion for a perfectly healthy woman and foetus. 
Any possible deleterious effects on the children as a result of the mother's impaired health could be covered by clause two. If extension to other members of the family is to be allowed then why not include husband, grandparents or even in-laws? That the child may be congenitally deformed is often a worry to a pregnant woman, sometimes amounting to a specific phobia, but an added factor may be found in cases where an unsuccessful attempt has been made at selfinduced abortion with possible damage to the foetus.

One or more of these conditions must be invoked by the two doctors who complete Certificate A, which is the official form for the purpose and which has to be completed before the operation is carried out. It has also to be preserved for 3 years afterwards. It should be noted that neither of the doctors need be a specialist or a consultant. An emergency procedure is also available under the Act when one medical practitioner is allowed to terminate a pregnancy where he is of the opinion that termination was immediately necessary to save the life or to prevent grave permanent injury to the physical or mental health of the pregnant woman.

All the above conditions apply to a pregnancy up to 28 weeks when the foetus is considered to be viable. From this time on the legal position is still regulated by the Infant Life (Preservation) Act 1929 which has not been repealed. This allows abortion only for preserving the life of the mother.

Obviously not all indications under the Act are going to be psychiatric but a high proportion will be. The purpose of the present paper is to report the author's experience during the first complete year of the Abortion Act by a descriptive study of all cases referred to him for a psychiatric opinion in connection with termination. This is to demonstrate possible trends, for further comparison with other workers' experience and as a basis for a follow-up study. The opportunity is also taken to compare this series with another seen during the year before the Act was implemented (Kenyon, 1969).

\section{Results}

There were sixty-five patients referred during the year under review; civil status and age are summarized in Table 1.

TABLE 1. Civil status and age

\begin{tabular}{|c|c|c|c|}
\hline Status & No. & $\%$ & Age (mean) \\
\hline $\begin{array}{l}\text { Single } \\
\text { Married } \\
\text { Separated/Divorced }\end{array}$ & $\begin{array}{r}32 \\
24 \\
9\end{array}$ & $\begin{array}{l}50 \\
36 \\
14\end{array}$ & $\begin{array}{l}19 \cdot 3 \text { years } \\
30 \cdot 2 \text { years }\end{array}$ \\
\hline Totals & 65 & 100 & $\begin{array}{r}24 \cdot 8 \text { (range } \\
15-43 \text { ) }\end{array}$ \\
\hline
\end{tabular}

Half were unmarried with a mean age of $19 \cdot 3$ years. A high proportion ( $27 \%$ ) of the 'ever married' group were either separated or divorced at the time of referral. Six $(9 \cdot 2 \%)$ were foreign born. Religious affiliation, as recorded on the case file, was as follows: $80 \%$ Church of England; $7 \cdot 7 \%$ Roman Catholic; $9.2 \%$ none and $3.1 \%$ 'other'; the latter consisting of one Sikh and one Muslim. These are only nominal but in every case during the course of the psychiatric interview it was ascertained whether or not they actually practised their stated religion; eleven $(20 \%)$ said that they did.

Referral was by the general practitioner in $60 \%$ of cases, gynaecologist $36 \%$ and 'other' $4 \%$. In relatively few cases was the referring doctor's own opinion given whether termination seemed indicated or not. Occasionally a patient was referred who had already been 'signed-up' by two general practitioners. As already pointed out according to the Abortion Act neither of the two doctors completing Certificate A need be specialists or consultants. But on the other hand one general practitioner wrote the following in his letter of referral...' I have made it quite clear (to the patient) that any decision must rest partly with you, and partly with the gynaecologist, and that your responsibilities are to make the Act work'.

Length of history for the presenting complaints was not always easy to determine although in some it was obviously as long as she had known she was pregnant. The mean length of history was 18.9 months with a range of 1 month to 17 years.

The family history and early development were gone into in some detail. In fourteen $(21 \%)$ they were only children; $6 \%$ were adopted and $3 \%$ illegitimate. In $17 \%$ the parents had been separated or divorced. Relationships with mother had been poor in just over half $(52 \%)$ and in $46 \%$ the mother herself had a history of psychiatric disturbance. Relationships with father had been poor in $40 \%$ and in $28 \%$ he, too, had had some psychiatric disturbance.

In exactly half their childhood was reported as being unhappy. Forty-eight per cent had left school by the age of 15 . Four patients $(6 \%)$ were Oxford University students: three undergraduates (two of these being in their final year) and one postgraduate.

The mean age of menarche was 12.8 years with a range of $10-17$ years. Half $(50 \%)$ reported some symptoms of premenstrual tension, $34 \%$ experienced irregular periods, $26 \%$ had significant dysmenorrhoea and $15 \%$ menorrhagia.

The mean age at first sexual intercourse was 18.4 years with a range of 14-25 years. The number of different sexual partners they had had in their lives is summarized for single patients in Table 2.

The extremes met with were one patient who had had intercourse only once in her life and promptly became pregnant, to another who had lost count of the number of different men she had slept with but 
TABLE 2. Sexual history of single patients

\begin{tabular}{lcc}
\hline \multicolumn{1}{c}{$\begin{array}{c}\text { No. of } \\
\text { different } \\
\text { sexual partners }\end{array}$} & \multicolumn{2}{c}{ Single patients } \\
\cline { 2 - 3 } & No. & $\%$ \\
\hline One only & 11 & $34 \cdot 3$ \\
Two & 12 & $37 \cdot 7$ \\
Three & 4 & $12 \cdot 5$ \\
Four & 3 & $9 \cdot 3$ \\
Four + & 2 & $6 \cdot 2$ \\
Totals & 32 & 100 \\
\hline
\end{tabular}

estimated 'over 70' but with two previous abortions. Four of the single patients had already had four previous pregnancies, all of which had gone to term and all the children being subsequently adopted.

For married patients $(N=33)$ the mean length of marriage was 9.4 years (range 1-20 years); just over half $(51 \%)$ were virgins on marriage. Seven $(21 \%)$ were pregnant on marriage and four had had six pregnancies premaritally; three of these ended in abortion (two illegal and one legal) and three children, all of whom were kept. In $73 \%$ the marriage was generally unhappy, with poor sexual adjustment in $57 \%$. Infidelity was admitted in $24 \%$. The mean number of children was 2.5 with a range of 0-5 (three patients had none) and 9\% had experienced a spontaneous abortion.

By the time they came for psychiatric consultation the mean length of pregnancy was 11.0 weeks with a range of 8-18 weeks. The parity of all patients, given separately for the single and married, is summarized in Table 3.

TABle 3. Parity of all patients

\begin{tabular}{cccccc}
\hline \multirow{2}{*}{ Present pregnancy } & \multicolumn{2}{c}{ Single patients } & & \multicolumn{2}{c}{ Married patients } \\
\cline { 2 - 3 } \cline { 5 - 6 } \cline { 5 - 6 } & No. & $\%$ & & No. & $\%$ \\
\hline 1st & 28 & $87 \cdot 5$ & & 1 & 3 \\
2nd & 4 & $12 \cdot 5$ & & 2 & 6 \\
3rd & - & - & & 12 & $36 \cdot 3$ \\
4th & - & - & & 7 & $21 \cdot 2$ \\
5th & - & - & & 4 & $12 \cdot 1$ \\
6th & - & - & & 5 & $15 \cdot 1$ \\
8th & - & - & & 2 & 6 \\
Totals & 32 & 100 & & 33 & 100 \\
\hline
\end{tabular}

Eight or $12 \%$ admitted trying to abort themselves. The husband was the father in twenty-three cases, i.e. in $70 \%$ of the married group. In those cases where the husband was not the father they had known the man concerned from extremes of one night to 4 years. In $78 \%$ no adequate contraceptive precautions had been taken but in fourteen $(21 \%)$ the presenting pregnancy seemed to be the result of a contraceptive failure. These were five on a contraceptive pill (all sequential preparations), six sheath, two cap and one pessary. Only one patient claimed to have been raped but this was not officially reported. Six $(9 \%)$ said they were drunk at the time they conceived.

Clinical estimation of intelligence is notoriously difficult but an attempt was made on a simple three point scale: superior $20 \%$, average $52 \%$, low $28 \%$. There was a previous psychiatric history in forty-five $(69 \%)$ and of these thirty-one had been treated by a general practitioner only and fourteen by a psychiatrist. The diagnostic assessment does not readily lend itself to a simple mutually exclusive classification but the following is an attempt (Table 4).

TABle 4. Psychiatric assessment

\begin{tabular}{lrc}
\hline Diagnosis & No. & $\%$ \\
\hline Depression & 34 & $52 \cdot 3$ \\
Nil gross psychiatric & 19 & $29 \cdot 3$ \\
Anxiety state & 6 & $9 \cdot 2$ \\
Psychopathic personality & 3 & $4 \cdot 6$ \\
Subnormal & 3 & $4 \cdot 6$ \\
Totals & 65 & 100 \\
\hline
\end{tabular}

There were no schizophrenics and the majority of the depressives were of the neurotic-reactive type. Those classified as 'nil gross psychiatric' in many cases had some personality problems, e.g. rebelling against authority. Eighteen $(28 \%)$ were considered to be suicidal risks.

Termination of pregnancy was recommended in thirty-two cases or $49 \%$ of the whole series. In twenty-six this was termination only and in six ter-? mination and sterilization. Sterilization only was advised in another two cases. Of those terminated thirteen were single and nineteen married representing 40 and $57 \%$, respectively, of the two groups. All of the recommendations were made primarily under clause 2 of the Abortion Act (risk of injury to mental health) with seven under clause 3 as well (risk to existing children). None was recommended solely on this latter clause, and although $27 \%$ were thought to be in danger of making a suicidal attempt the actual risk to life was difficult to evaluate so clause 1 was not used.

\section{Discussion}

A direct comparison may be made with the author's previous series (Kenyon, 1969) for the year 1967 , i.e. before the implementation of the Act, to see if any differences are highlighted. Actual numbers are very similar (sixty-one and sixty-five, respectively) but there are slightly more single patients in the current series as well as more separated and divorced (50 and $42 \%$ single, 14 and $12 \%$ separated or divorced). There is a drop in the proportion of foreign born (from 15 to $9 \%$ ) and also in Roman Catholics (from 16 to $8 \%$ ).

There is a slight increase in the proportion referred by general practitioners, from 56 to $60 \%$. 
What has altered is the length of history which has gone up from a mean of 2.8 months in 1967 to 18.9 months. Early history and family relationships show similar trends with more disturbances in relation to their mothers as well as more psychiatric morbidity on the maternal side. Similar proportions left school by age 15 and in 1967 there were five University students compared with four in the current series.

Sexual and marital histories were also very similar. The mean length of pregnancy $(11.0$ weeks $)$ by the time of consultation was exactly the same and so was the parity of the married women as in both series the peaks were 3rd, 4th and 6th in that order. In single patients the proportion of first pregnancies increased from 71 to $87 \%$. Overall there were the same number of contraceptive failures $(21 \%)$.

The proportion having a previous psychiatric history increased from 59 to $69 \%$ as also the proportions previously treated by a psychiatrist (from 17 to $31 \%$ ). Final diagnostic assessment shows a similar pattern with no psychotics in either series and 57 and $52 \%$, respectively, in the neurotic depressive category. In $1967,33 \%$ were considered suicidal risks compared with $28 \%$. Finally in the previous series $46 \%$ were recommended for termination compared with $49 \%$ after the Abortion Act.
There are, as yet, few other statistics available concerning the implementation of the Act, particularly solely on psychiatric recommendations. It is clear, though, that clause 3 (for existing children) by itself is not often being invoked $(4 \%$ of all notified abortions), while over $70 \%$ used clause 2 , these trends being in keeping with the present series.

Notifications for the 2nd and 3rd quarters of 1968 showed that $47 \%$ were single, $45 \%$ married and $8 \%$ widowed, separated or divorced. Corresponding figures for the present series were 50, 36 and $14 \%$. That there should be a high ratio of separated and divorced in an entirely psychiatric series is to be expected, but at least one commentator has expressed surprise at the high proportion of 'women without husbands' having abortions (Lewis, 1969). The lack of adequate contraceptive precautions is in accord with another recently published series (Diggory, 1969).

\section{References}

DiggoRY, P.L.C. (1969) Some experiences of therapeutic abortion. Lancet, $1,873$.

KENYON, F.E. (1969) Termination of pregnancy on psychiatric grounds: a comparative study of sixty-one cases. Brit. J. med. Psychol. 42, part 3.

LewIS, T.L.T. (1969) The Abortion Act. Brit. med. J. 1, 241. 